\title{
O PROCESSO DE ASSOCIAÇÃO ENTRE MARCAS E GERADORES DE CONTEÚDO NO YOUTUBE: CASOS BRASILEIROS
}

\section{THE MARKET PROCESS OF ASSOCIATION BETWEEN BRANDS AND CONTENT GENERATOR ON YOUTUBE: BRAZILIAN CASES}

\section{Durval Lucas Júnior}

Doutor em Administração pela Faculdade de Economia, Administração e Contabilidade da Universidade de São Paulo - USP (Brasil). E-mail: durval@ufscar.br

\section{Camila Mayumi Adati}

Bacharel em Administração pela Universidade Federal de São Carlos - UFSCAR, São Paulo (Brasil). E-mail: camila adati@hotmail.com

\section{Bárbara de Lima}

Bacharel em Administração pela Universidade Federal de São Carlos - UFSCAR, São Paulo (Brasil). E-mail: baa.lima@hotmail.com 


\title{
O PROCESSO DE ASSOCIAÇÃO ENTRE MARCAS E GERADORES DE CONTEÚDO NO YOUTUBE: CASOS BRASILEIROS
}

\section{RESUMO}

O desenvolvimento das tecnologias da informação e comunicação fez com que os geradores de conteúdo nas redes sociais ganhassem destaque perante o público. Diversas empresas começaram a perceber que ao se associar aos geradores de conteúdo, elas poderiam se aproximar de seu público-alvo e aumentar o volume de vendas, por um custo inferior se comparado às mídias tradicionais. $\mathrm{O}$ objetivo deste artigo é compreender e descrever o processo de associação entre marcas e geradores de conteúdo. Para isso, utilizou-se o estudo de casos múltiplos. Os resultados revelam que este processo pode ser dividido em cinco etapas principais: Contato, Negociação, Ação, Remuneração, e Avaliação e Manutenção de relacionamento. Por fim, é possível concluir que esse tipo de associação está crescendo, tornando-se uma nova opção para as empresas comunicarem com os consumidores, assim como se tornou para os geradores de conteúdo, uma fonte de renda e uma forma para conquistar notoriedade.

Palavras-chave: Associação de marca. Relacionamento comercial. Redes sociais. Geradores de conteúdo. Novas mídias.

\section{THE MARKET PROCESS OF ASSOCIATION BETWEEN BRANDS AND CONTENT GENERATOR ON YOUTUBE: BRAZILIAN CASES}

\begin{abstract}
The development of the information and communication technologies allowed many content generators on the internet to gain notoriety with the audience. Several organizations started to notice that the association with this kind of users could make them get closer to their target audience and raise the sales volume for relatively low cost. The aim of this paper is to comprehend and describe the process of association between brands and content generators. For this purpose, the multiple case study method has been used. The main outcome is that the process is divided in five main steps: Contact, Negotiation, Action, Payment, and Evaluation and relationship maintenance. It is also possible to highlight that this kind of association is growing, becoming a new option for organizations to communicate with their consumers; on the other hand, it could be an additional source of income to the content generators and a way they can gain notoriety.
\end{abstract}

Keywords: Brand association. Commercial partnership. Social networking sites. User generated content. New medias. 


\section{INTRODUÇÃO}

Recentemente, é possível perceber a frequente menção e presença de marcas em vídeos gerados por usuários no YouTube. Empresas de diversos segmentos começaram a perceber que a associação a geradores de conteúdo pode ser uma maneira de alcançar o seu público, posicionar a marca e aumentar o volume de vendas, por um custo relativamente baixo (Carreira, 2014; Monçale, Gomes \& Arruda Neto, 2015).

Primeiramente, é preciso compreender que esse processo de associação ocorre por fazer parte da estratégia da comunicação da empresa, e que a utilização da comunicação integrada de marketing implica na diversificação dos métodos de comunicação, incluindo a divulgação no meio online (Kotler \& Keller, 2011). Neste sentido, o YouTube é uma comunidade de conteúdo referência em seu segmento, pois nesta mídia há uma grande geração de conteúdo pelos usuários (Oh, Susarla \& Tan, 2008), enquanto que os youtubers são os usuários que geram conteúdo no YouTube, e se destacam dos demais pois acabam com a divisão entre amadores e profissionais, ao terem um público definido e notoriedade em temas específicos, além de utilizarem técnicas para produzir conteúdo. Consequentemente, alguns destes usuários compartilham publicidade e obtêm receitas por meio da geração de conteúdo (Burgess \& Green, 2009).

Observa-se que as empresas passaram a perceber grande oportunidade ao se associarem a estes geradores de conteúdo no YouTube, visto que o vídeo é um formato extenso e rico, que está em ascensão, e permite que as empresas realizem uma publicidade criativa, de modo que a marca venha a ser notada (Shao, 2009).

Desta forma, o objetivo do presente artigo é compreender e descrever o processo de associação entre marcas e geradores de conteúdo no YouTube. Para tanto, foi realizada uma pesquisa qualitativa, de caráter descritivo, e que utiliza a estratégia de casos múltiplos. Os dados secundários foram coletados por meio da observação sistemática dos principais canais ligados ao segmento de moda e beleza; os dados primários foram obtidos por meio de entrevistas semiestruturadas com youtubers e empresas com as quais estes se relacionam.

Acredita-se que, uma vez tendo este processo devidamente mapeado, tanto as empresas quanto os youtubers poderão conhecer melhor este fluxo e poderão adequar suas estratégias, associando-se de maneira mais eficiente e gerando um maior retorno para ambas as partes.

Do ponto de vista de sua organização, o artigo está estruturado em cinco seções, incluindo esta Introdução. A seguir, apresenta-se a Revisão de Literatura, descreve-se a Metodologia utilizada, realiza-se a Análise e Discussão dos Resultados e, por fim, são apresentadas as Considerações Finais.

\section{REVISÃO DE LITERATURA}

Esta pesquisa está fundamentada em dois pilares básicos: o primeiro pilar trata da ascensão da comunicação de marketing online como parte da evolução da comunicação de marketing, enquanto que o segundo pilar trata da importância do YouTube como plataforma de comunicação baseada na Web 2.0, a ascensão dos youtubers como propagadores de mensagens, inclusive mercadológicas e, consequentemente, a necessidade de as organizações se associares a estes geradores de conteúdo com vistas a estruturar o processo de comunicação de marketing nas plataformas de redes sociais.

Desta forma, as duas subseções a seguir visam organizar o raciocínio que fundamenta a elaboração desta revisão de literatura e, consequentemente, a pesquisa como um todo.

Revista de Gestão e Secretariado - GeSec, São Paulo, v. 8, n. 3, p 228-248, Mai./Ago. 2017. 


\subsection{Comunicação de Marketing Online}

Segundo Belch G. e Belch M. (2008), a comunicação existe em todos os elementos do mix de marketing. Porém, as comunicações da empresa para o mercado são parte de um programa controlado de promoção. Potluri (2008), ao apresentar os elementos que compõem o mix de comunicação de marketing - propaganda, contato pessoal, publicidade e relações públicas, promoção de vendas, materiais instrucionais e corporate design - destaca o papel do mix de comunicação de marketing para o alcance do objetivo organizacional de adicionar valor ao produto ou serviço, garantindo que o cliente/consumidor faça a melhor aquisição possível. Gurau (2008), por sua vez, reforça que o foco no valor da marca requer uma mudança nas perspectivas do marketing e da comunicação, enquanto Winer (2009) destaca as ferramentas e sistemas de comunicação de marketing.

Enquanto Rowley (2004) ressalta a atuação das organizações no ambiente Web 1.0, Parise e Guinan (2008) definem a Web 2.0 como um fenômeno social no qual os consumidores estão com o controle, direcionando o conteúdo para construir relações pessoais. Constantinides e Fountain (2008), por sua vez, afirmam que, na Web 2.0, as preferências e experiências dos clientes sobre produtos e serviços não se baseiam apenas em informações fornecidas por meio da mídia tradicional, ou dos sites corporativos, mas em resenhas de outros usuários, postagens em blogs e redes sociais, fóruns online e outras maneiras de discussão - que não são controladas pelas marcas, mas geradas pelos próprios usuários. Ou seja, utilizando as redes sociais, os consumidores podem pesquisar sobre os produtos e marcas, bem como defender produtos e organizações que gostam (Pookulangara \& Koesler, 2011).

A conversa informal sobre marcas e produtos nas mídias sociais é chamada de boca-aboca online (e-Word of Mouth) e influencia diversos aspectos do comportamento do consumidor, tais como comportamento de compra, construção e percepção da marca, aquisição de clientes, e volume de vendas. O boca-a-boca online possui um alto impacto, pois permite uma comunicação rápida entre os usuários e a conexão com diversas pessoas, grupos e comunidades (Bughin, Doogan \& Vetvik, 2010; Casaló, Flavián \& Guinalíu, 2011; Chu \& Kim, 2011).

De acordo com Sebastião (2011), os consumidores preferem ver publicidade nos meios mais passivos, como a imprensa escrita - revistas e jornais -, e menos em meios como a internet, a rádio e o e-mail. Singh, Veron-Jackson e Cullinane (2008) destacam que, diante destas mudanças no comportamento do consumidor, as empresas precisam se diferenciar, sendo o marketing uma importante ferramenta, que pode ser utilizada para promover não apenas produtos e marcas, mas também sentimentos e experiências do cliente com o produto. Bolotaeva e Cata (2011), por sua vez, destacam as oportunidades para as empresas se envolverem nas comunidades, continuarem a pesquisar sobre como se inserir nas redes sociais, e procurarem adaptar sua estratégia para os dispositivos móveis.

Diversas organizações, ao utilizarem mídias sociais, se preocupam em criar uma página no Facebook e uma conta no Twitter, ou colocar anúncios no YouTube. No entanto, tais ações não são suficientes para alcançar e engajar o público, principalmente a geração Y, que cresceu em contato com estas mídias (Berthon, Pitt, Plangger \& Shapiro, 2011). Segundo Fournier e Avery (2011), o branding nas mídias sociais ocorre por meio do empoderamento dos consumidores. Assim, as empresas com os melhores desempenhos nas redes sociais procuram interagir de forma natural nas conversas na Web 2.0, sendo a maior meta a criação de conversas ressonantes, e não apenas a observação do comportamento do consumidor.

Segundo Parise e Guinan (2008), grande parte das empresas concorda que os conteúdos gerados pelos usuários estão desempenhando um papel cada vez mais importante

Revista de Gestão e Secretariado - GeSec, São Paulo, v. 8, n. 3, p 228-248, Mai./Ago. 2017. 
nas considerações da estratégia de marketing. Assim, as empresas estão cada vez mais focadas em pesquisar sobre blogs, redes sociais e vídeos caseiros. Para elas, é fundamental monitorar e reconhecer o conteúdo criado por esses usuários e trabalhar com esses consumidores, ao invés de tentar impedir a divulgação de informações sobre produtos que não são geradas pela empresa.

Fernandes e Rosa (2013) afirmam que a possibilidade de se mensurar dados com maior precisão é uma valiosa contribuição que o ambiente Web 2.0 proporciona para as organizações, e que essa mensuração pode ocorrer por meio de ferramentas como Google Analytics, Google Adwords, ou ferramentas existentes dentro das próprias redes sociais.

Diante deste contexto, é importante que as empresas reconheçam a necessidade de se envolver nas mídias sociais e definam cuidadosamente suas estratégias de marketing. Esse tipo de mídia oferece diversas oportunidades para que as empresas escutem seus consumidores, peçam opiniões, e também estabeleçam parcerias com eles. As empresas devem visualizar as mídias sociais como um componente fundamental no seu mix de comunicação de marketing, e também devem integrá-las à sua proposta de comunicação, visando aumentar o valor da organização para o cliente. O conteúdo gerado pelo usuário relacionado aos produtos e marcas, cada vez mais irá influenciar o valor das marcas no futuro (Bruhn, Schoenmueller \& Schafer, 2012).

De fato, algumas empresas já adaptaram suas estratégias de mercado-alvo pensando em alcançar os geradores de conteúdo e os influenciadores. Ao estabelecer parcerias com essas pessoas, busca-se que as mensagens geradas reflitam os sentimentos verdadeiros dos usuários sobre produtos e serviços, e também que os consumidores acreditem que essa informação é mais confiável do que as mensagens criadas pelas agências de publicidade (Constantinides \& Fountain, 2008).

\subsection{YouTube}

Criado em 2005, o YouTube é uma comunidade de conteúdo, onde os usuários podem criar e se inscrever em canais, além de visualizar, comentar, avaliar e postar vídeos (Smith, Fischer \& Yonjian, 2012).

No YouTube, podem ser identificados três perfis de usuários: os consumidores, os participantes, e os produtores. Entre esses perfis, destacam-se os produtores, pois sem a produção e geração de novos conteúdos, tais mídias não existiriam. Dentre as motivações para produzir conteúdo estão a autoatualização, a autorrealização, o desejo por fornecer informações úteis para outros membros da comunidade e, principalmente, a expressão própria e a busca por aumento da fama, influência e status (Dhar \& Chang, 2009; Shao, 2009).

Os usuários produtores de conteúdo, por sua vez, podem ser classificados em três grupos: grande mídia, web TV e usuários comuns. Enquanto a grande mídia se refere a canais e programas que já estão presentes na indústria da música e do cinema, as empresas webTV são aquelas que se espelham na TV tradicional e produzem programas para um nicho específico, distribuindo-os por meio da internet. Os usuários comuns, por fim, não representam nenhuma organização, sendo inicialmente identificados como amadores. Ao analisar de modo mais profundo os usuários identificados como comuns, notou-se que é possível dividi-los em cinco perfis: participantes iniciais, usuários casuais, participantes ativos, youtubers e celebridades do YouTube (Burgess \& Green, 2009).

Os youtubers e celebridades do YouTube podem ser destacados dos demais, pois são usuários que revelam um modo inovador de gerar conteúdo e interagir nesta mídia. Enquanto os youtubers são aqueles que possuem um canal e produzem vídeos com diversos temas -

Revista de Gestão e Secretariado - GeSec, São Paulo, v. 8, n. 3, p 228-248, Mai./Ago. 2017. 
como receitas, tutoriais, games e vlogs -, são consideradas celebridades do YouTube aqueles que possuem um grande número de inscritos e são marcas consolidadas dentro do site. Estes usuários rompem a divisão entre amadores e profissionais, pois ao mesmo tempo em que são usuários comuns, são quase produtores profissionais, pois possuem um público definido, notoriedade em temas específicos, e utilizam técnicas para produzir vídeos e engajar pessoas. Também podem ser identificados como empreendedores, pois além de gerarem conteúdo, compartilham publicidade e obtêm receitas por meio da presença online (Burgess \& Green, 2009).

\subsubsection{Associações de marca na comunidade de conteúdo YouTube}

Por meio da veiculação de vídeos no YouTube, uma ferramenta mais criativa para fazer publicidade (Drury, 2008), uma organização pode alcançar um grande número de espectadores. No entanto, neste ambiente, as marcas ocupam um papel periférico. Os principais modos como as marcas podem ser mencionadas em vídeos no YouTube são: reviews (avaliações de produtos); opiniões em vlogs; "unboxing" (desempacotamento de novos produtos); propagandas amadoras, sátiras e paródias; demonstrações de consumo (como tutoriais); e cobertura de eventos da marca. Desta forma, o YouTube favorece a disseminação tanto de informações factuais, quanto de opiniões sobre as marcas, e mesmo que elas não ocupem o papel central, o formato vídeo permite que elas sejam notadas (Smith et al., 2012).

A marca também associa sua imagem, pode reafirmar sua identidade e se personalizar utilizando-se de formadores de opinião que traduzam o lifestyle da marca, contando com a credibilidade que estes indivíduos possuem com sua audiência (Carreira, 2014; Pinho \& Ferreira, 2014). Esta associação também é positiva para os geradores de conteúdo, pois além de ser um negócio rentável, possibilita o aumento da sua notoriedade (Monçale et al., 2015), podendo também oferecer experiências e produtos que devem resultar em novos conteúdos e, consequentemente, mais acessos (Hinerasky, 2014).

Essa relação entre marca e geradores de conteúdo pode se iniciar com o envio de produtos e lançamentos da marca, para que os geradores de conteúdo conheçam as novidades do mercado, testem, e apresentem ao público, realizando uma publicidade indireta (Pinho \& Ferreira, 2014; Castro, 2013). Também pode se formalizar e se tornar rentável por meio da utilização de diferentes formatos, como a criação de conteúdo para as mídias sociais da marca, participação em eventos, participação em campanhas publicitárias, co-criação de produtos, e inserção de produtos da marca no conteúdo - prática conhecida como publipost (Didone, 2014; Hinerasky, 2014, Monçale et al., 2015).

$O$ processo atual de associação entre marcas e geradores não é claro e bem estabelecido. Segundo Didone (2014), há marcas que são parceiras contínuas de certos geradores, com contratos estabelecidos, e há parceiros que realizam apenas ações pontuais. As marcas interessadas entram em contato com os geradores de conteúdo, e enviam materiais e informações complementares sobre a empresa e seus produtos. Em seguida, o gerador avalia a compatibilidade da marca com o seu público, e decide se deseja realizar esta parceria. Caso positivo, é desenvolvido um projeto, que define quais os formatos de divulgação mais interessantes a se utilizar.

Enquanto geradores reconhecidos são procurados pelas marcas, há geradores de conteúdo iniciantes, que iniciam o contato com as empresas para firmar parcerias, assumindo uma postura mais ativa (Castro, 2013). Blogs que possuem notoriedade possuem um media kit, que contém informações concretas e comprováveis que demonstram suas qualidades e

Revista de Gestão e Secretariado - GeSec, São Paulo, v. 8, n. 3, p 228-248, Mai./Ago. 2017. 
potenciais, como perfil do público, número de acessos, preços, formas de negociação e contato. O media kit é enviado para a empresa após o primeiro contato com o blog, no entanto não se sabe se youtubers também possuem este tipo de material e o utilizam no momento de estabelecer parcerias e relações comerciais (Monçale et al., 2015).

Os geradores de conteúdo devem se atentar ao estabelecer relações comerciais e inserir conteúdo publicitário no conteúdo usual. A realização de publiposts pode ser considerada uma prática controversa, pois muitas pessoas acreditam nas opiniões e podem ser influenciadas sem saber que se trata de publicidade (Carreira, 2014; Monçale et al., 2015). Se for caracterizada como marketing oculto (Neisser, 2004), pode comprometer a credibilidade e o poder de influência do gerador de conteúdo (Carreira, 2014; Dhar \& Chang, 2009).

Os geradores de conteúdo que estão se profissionalizando possuem a responsabilidade de fornecer valor agregado aos demais usuários, de modo a atrair mais pessoas para visualizar e interagir com o conteúdo produzido. Conteúdo este que não deve ser promocional e igual ao marketing tradicional, mas casual e divertido, com temas interessantes para o seu público, bem gerido, e atualizado regularmente (Schmallegger \& Carson, 2007).

Por fim, ao se associarem às marcas, é importante que os geradores de conteúdo busquem a coesão entre marca, estilo do canal, e público, para que a ação possua o retorno esperado (Didone, 2014; Monçale et al., 2015). Castro (2013) recomenda que os geradores de conteúdo administrem as expectativas e objetivos dos integrantes de sua rede, para que possam atrair mais visitantes e parceiros, crescendo e sendo bem-sucedidos.

Os principais elementos observados na literatura, e que subsidiam a investigação acerca do processo de associação entre marcas e geradores de conteúdo no YouTube, estão apresentados no Quadro 1 a seguir:

\section{Quadro 1: Decorrências da literatura sobre o processo de associação entre marcas e geradores de conteúdo no YouTube}

\begin{tabular}{|c|c|c|}
\hline Elementos Observados & Descrição / Detalhamento & Principais Autores \\
\hline $\begin{array}{l}\text { Diferenciais dos } \\
\text { youtubers }\end{array}$ & $\begin{array}{l}\text { Formatos diversos de vídeos; } \\
\text { Compartilhamento de publicidade; } \\
\text { Obtenção de receitas via presença online. }\end{array}$ & $\begin{array}{l}\text { Burgess \& Green } \\
\text { (2009); Drury (2008); } \\
\text { Monçale et al. (2015) }\end{array}$ \\
\hline \multirow{2}{*}{ Ator origem da parceria } & Marcas interessadas no processo de associação & Didone (2014) \\
\hline & Geradores de conteúdo iniciantes & Castro (2013) \\
\hline \multirow[t]{2}{*}{$\begin{array}{l}\text { Procedimentos possíveis } \\
\text { a se adotar no } \\
\text { estabelecimento de } \\
\text { associações entre } \\
\text { empresas e youtubers }\end{array}$} & $\begin{array}{l}\text { Contato das marcas com os youtubers; Envio de } \\
\text { materiais e informações sobre a empresa e seus } \\
\text { produtos; Avaliação pelo youtuber acerca da } \\
\text { compatibilidade da marca com o seu público; } \\
\text { Decisão sobre realização da parceria; Definição de } \\
\text { formatos de divulgação a utilizar. }\end{array}$ & Didone (2014) \\
\hline & Envio de media kit para as empresas & Monçale et al. (2015) \\
\hline \multirow{2}{*}{$\begin{array}{l}\text { Tipos possíveis de } \\
\text { parceria }\end{array}$} & Envio de produtos e lançamentos da marca & $\begin{array}{l}\text { Pinho \& Ferreira (2014) } \\
\text { Castro (2013) }\end{array}$ \\
\hline & $\begin{array}{l}\text { Criação de conteúdo para as mídias sociais da marca; } \\
\text { Participação em eventos; Participação em campanhas } \\
\text { publicitárias; Co-criação de produtos; Publiposts. }\end{array}$ & $\begin{array}{l}\text { Didone (2014) } \\
\text { Hinerasky (2014) } \\
\text { Monçale et al. }(2015)\end{array}$ \\
\hline $\begin{array}{l}\text { Formas de execução da } \\
\text { ação de comunicação }\end{array}$ & $\begin{array}{l}\text { Reviews; Opiniões em vlogs; Unboxing; } \\
\text { Propagandas, sátiras e paródias; Tutoriais; Eventos }\end{array}$ & $\begin{array}{l}\text { Smith et al. (2012) } \\
\text { Hinerasky (2014) }\end{array}$ \\
\hline \multirow{3}{*}{ Processos de avaliação } & Formato do conteúdo diferente do convencional & $\begin{array}{l}\text { Schmallegger \& Carson } \\
\text { (2007) }\end{array}$ \\
\hline & $\begin{array}{l}\text { Busca de coesão entre marca, estilo do canal e } \\
\text { público; Administração de expectativas e os objetivos; }\end{array}$ & $\begin{array}{l}\text { Didone (2014) } \\
\text { Monçale et al. (2015) }\end{array}$ \\
\hline & Atração de visitantes e parceiros. & Castro, 2013 \\
\hline
\end{tabular}

Fonte: Elaborado pelos autores (2015). 


\section{METODOLOGIA}

O tipo de pesquisa adotada neste trabalho foi a qualitativa de caráter descritivo (Gil, 2008; Prodanov \& Freitas, 2013). A estratégia de estudo adotada foi o estudo de múltiplos casos (Yin, 2001).

Os dados secundários foram coletados por meio da observação sistemática da plataforma de conteúdo audiovisual YouTube. Para tanto, foram selecionados os dez canais com maior número de inscritos na categoria moda e beleza, e foram assistidos os vídeos publicados em tais canais entre os meses de maio e julho de 2015, totalizando 268 vídeos, com duração de 7 horas e 4 minutos. A partir daí, foram identificadas as principais práticas entre os canais deste segmento, ou seja, quais são os principais formatos de conteúdo, os tipos de vídeos que possuem maior número de visualizações e engajamento, bem como quais são as principais marcas mencionadas, e em que contextos estão inseridas no conteúdo criado.

Os dados primários foram coletados por meio de entrevistas semiestruturadas (Boni \& Quaresma, 2005), com geradores de conteúdo do YouTube, conhecidos como youtubers (Apêndice 1, seção 1.1), e empresas com as quais estes se relacionam (Apêndice 1, seção 1.2). Os critérios utilizados para a escolha destes entrevistados foram o segmento ao qual o canal pertence e o número de assinantes que o canal possui. Assim, foram selecionados youtubers que produzem vídeos do segmento de moda e beleza, e cujos canais possuem, no mínimo, 300 mil inscritos. Constatou-se que este é um número relevante de inscritos, já que os maiores canais de beleza, que possuem notoriedade e são visados pelas marcas, aproximam-se ou superam este número.

Para as entrevistas, foram selecionadas marcas que adotam a associação com geradores de conteúdo como parte de suas atividades de comunicação de marketing. Tais marcas foram identificadas ao serem citadas em vídeos assistidos durante a coleta de dados secundários, e ao serem mencionadas pelos próprios youtubers, no momento da entrevista, como marcas com quem possuem relacionamento comercial ou parcerias.

As entrevistas, tanto com youtubers, quanto com empresas, realizaram-se pessoalmente, por telefone, e-mail e aplicativos de mensagens instantâneas, no período de setembro a outubro de 2015. Com base em roteiros semiestruturados (Apêndice 1) ambas as partes foram questionadas sobre o processo de associação entre geradores de conteúdo e empresas, e as práticas comerciais e publicitárias envolvendo a mídia social YouTube.

Para a análise dos dados foi utilizada a triangulação de métodos (Minayo, Assis \& Sousa, 2010). Neste trabalho, esses fatores podem ser representados respectivamente pelos dados obtidos por meio das entrevistas, a revisão de literatura e a observação sistemática do ambiente realizada no YouTube. Além disso, conforme preconizado por Yin (2001), a realização de entrevistas com todos os membros integrantes do processo de associação visou a descrição objetiva do processo como um todo, sem que houvesse vieses de origem que comprometessem a descrição do processo que se constitui no objetivo desta pesquisa.

Por razões estratégicas e de sigilo, as organizações e seus funcionários, bem como os geradores de conteúdo que colaboraram com o presente estudo não serão identificados, sendo caracterizados a seguir:

- Youtuber 1: maquiadora profissional, está no YouTube desde 2010 e possui um canal com 389.409 inscritos e mais de 37 milhões de visualizações. Seu público é composto em sua maioria por mulheres jovens e adultas. A Youtuber 1 é parceira da Empresa A.

- Youtuber 2: designer de joias, está no YouTube desde 2010 e possui um canal com 349.716 inscritos e mais de 23 milhões de visualizações. Seu público é composto em sua maioria por mulheres. A Youtuber 2 é parceira da Empresa B. 
- Youtuber 3: formada em fotografia, está no YouTube desde 2011 e possui um canal com 599.782 inscritos e mais de 23 milhões de visualizações. Seu público é composto em sua maioria por mulheres, adolescentes, jovens e adultas. A Youtuber 3 é parceira das Empresas C e D.

As principais características de cada youtuber estão presentes no Quadro 2.

Quadro 2: Youtubers participantes da pesquisa

\begin{tabular}{|l|c|c|c|c|c|}
\hline & Profissão & $\begin{array}{c}\text { Início no } \\
\text { YouTube }\end{array}$ & $\begin{array}{c}\text { Número de } \\
\text { Inscritos * }\end{array}$ & $\begin{array}{c}\text { Número de } \\
\text { visualizações* }\end{array}$ & Empresa \\
\hline Youtuber 1 & Maquiadora & 2010 & 389.409 & 37 milhões & Empresa A \\
\hline Youtuber 2 & Designer de joias & 2010 & 349.716 & 23 milhões & Empresa B \\
\hline Youtuber 3 & Fotógrafa & 2011 & 599.782 & 23 milhões & Empresa C e D \\
\hline
\end{tabular}

*Dados coletados no dia 14/11/2015

Fonte: Elaborado pelos autores (2015).

- Empresa A: loja virtual com sede em Londrina/PR, atuando em âmbito nacional, sendo especializada na venda de maquiagens, cosméticos e acessórios para beleza.

- Empresa B: loja virtual com sede na cidade do Rio de Janeiro/RJ, atuando em âmbito nacional, sendo especializada na venda de acessórios e bijuterias. Também comercializa seus produtos por meio de revendedoras.

- Empresa C: loja virtual com sede na cidade de São Paulo/SP, especializada na produção e comercialização de maquiagens em parceria com blogueiras e youtubers.

- Empresa D: marca de cosméticos com sede em Mogi das Cruzes/SP. Distribui seus produtos em âmbito nacional, sendo especializada na comercialização de maquiagens, acessórios para maquiagem e produtos para cabelos.

O quadro 3 sintetiza as principais características das empresas que participaram desta pesquisa:

\section{Quadro 3: Empresas participantes da pesquisa}

\begin{tabular}{|c|c|c|c|c|c|}
\hline & $\begin{array}{c}\text { Tipo de } \\
\text { Empresa }\end{array}$ & Localização & Produtos & $\begin{array}{c}\mathbf{N}^{\mathbf{0}} \text { de } \\
\text { inscritos* }\end{array}$ & Youtuber \\
\hline Empresa A & Loja Virtual & Londrina & $\begin{array}{c}\text { Maquiagens, cosméticos } \\
\text { e acessórios de beleza }\end{array}$ & $\begin{array}{c}\text { Não possui } \\
\text { canal no } \\
\text { YouTube }\end{array}$ & Youtuber A \\
\hline Empresa B & Loja Virtual & Rio de Janeiro & Acessórios e bijuterias & 133 & Youtuber B \\
\hline Empresa C & Loja Virtual & São Paulo & Maquiagens & $\begin{array}{c}\text { Não possui } \\
\text { canal no } \\
\text { YouTube }\end{array}$ & Youtuber C \\
\hline Empresa D & Fabricante & $\begin{array}{c}\text { Mogi das } \\
\text { Cruzes }\end{array}$ & $\begin{array}{c}\text { Maquiagens e acessórios } \\
\text { para maquiagens }\end{array}$ & 23.843 & Youtuber C \\
\hline
\end{tabular}

*Dados coletados no dia 14/11/2015.

Fonte: Elaborado pelos autores (2015).

\section{ANÁLISE E DISCUSSÃO DOS RESULTADOS}

O processo de associação entre marcas e geradores de conteúdo no YouTube, observado nesta pesquisa divide-se em 5 etapas: Contato, Negociação, Ação, Remuneração, e 
Avaliação e Manutenção do Relacionamento. A síntese da estrutura geral do processo está representada graficamente pela Figura 1:

Figura 1: Processo de associação entre marcas e geradores de conteúdo

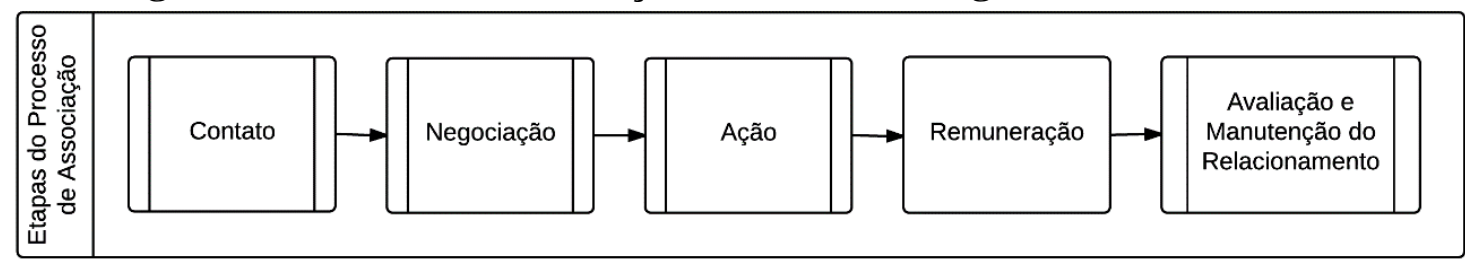

Fonte: Elaborado pelos autores (2015).

Cada etapa será detalhada a seguir, apresentando as subetapas que a compõem, bem como os fatores envolvidos em cada uma delas. Além disso, o processo aqui descrito vê a associação entre marcas e geradores de conteúdo não apenas como uma parceria, mas como uma relação comercial.

\subsubsection{Contato}

Por meio deste monitoramento, as marcas definem quais são os geradores de conteúdo que são considerados interessantes para associação. Além dos números de seguidores, comentários e visualizações, as marcas também costumam avaliar o perfil do gerador de conteúdo, a fim de saber se possui credibilidade, coerência, reconhecimento e aceitação do público. O trabalho deste gerador também é analisado, pois é necessário saber que tipos de conteúdo e formatos de vídeos são criados, e se estão de acordo com a ação que a empresa deseja realizar e o objetivo que deseja alcançar. Outro aspecto importante é o público atingido por este gerador de conteúdo, ou seja, tal público deve ser compatível com o público-alvo da marca.

A Empresa D, por exemplo, afirma que seleciona estrategicamente os geradores de conteúdo para se associar, considerando o perfil do gerador, o projeto que será realizado e o objetivo que deseja alcançar. A Empresa A, por sua vez, concorda com tal opinião ao afirmar que no seu caso, deseja ser reconhecida como uma marca séria e confiável, e deste modo busca parceiros que correspondam a este objetivo.

Conforme processo apresentado na figura 2A, após definir quem são os geradores de conteúdo com os quais deseja se associar, a marca realiza um contato inicial e solicita maiores informações sobre o trabalho do youtuber, bem como seu media kit. A partir das entrevistas realizadas, constatou-se que o media kit também é utilizado por youtubers, pois costuma incluir informações das diversas mídias em que o gerador de conteúdo está presente, seja blog, redes sociais (Facebook, Instagram) ou canal no YouTube, pois no momento de se associar, a empresa pode contratar a inserção da sua marca em conteúdos diversos, incluindo mais de uma mídia social. Assim como mencionado por Castro (2013), há casos em que geradores de conteúdo, geralmente iniciantes, procuram as marcas para se associarem. Nestes casos, conforme ilustrado na figura $2 \mathrm{~B}$, o youtuber entra em contato com as marcas, e caso haja interesse, esta solicita o media kit. 
Figura 2A: Subprocesso Contato Inicial Empresas

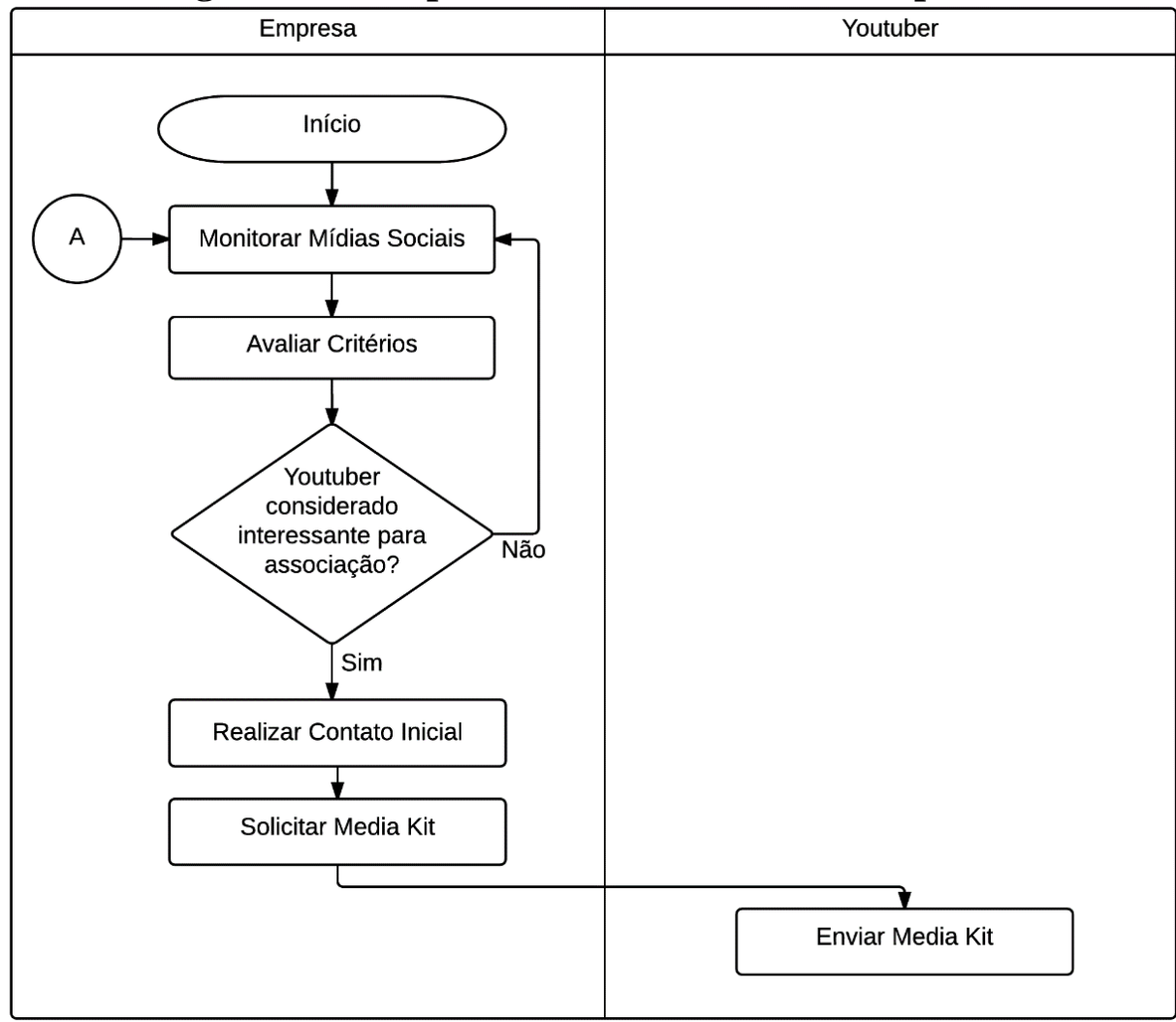

Fonte: Elaborado pelos autores (2015)

Figura 2B: Subprocesso Contato Inicial Youtuber

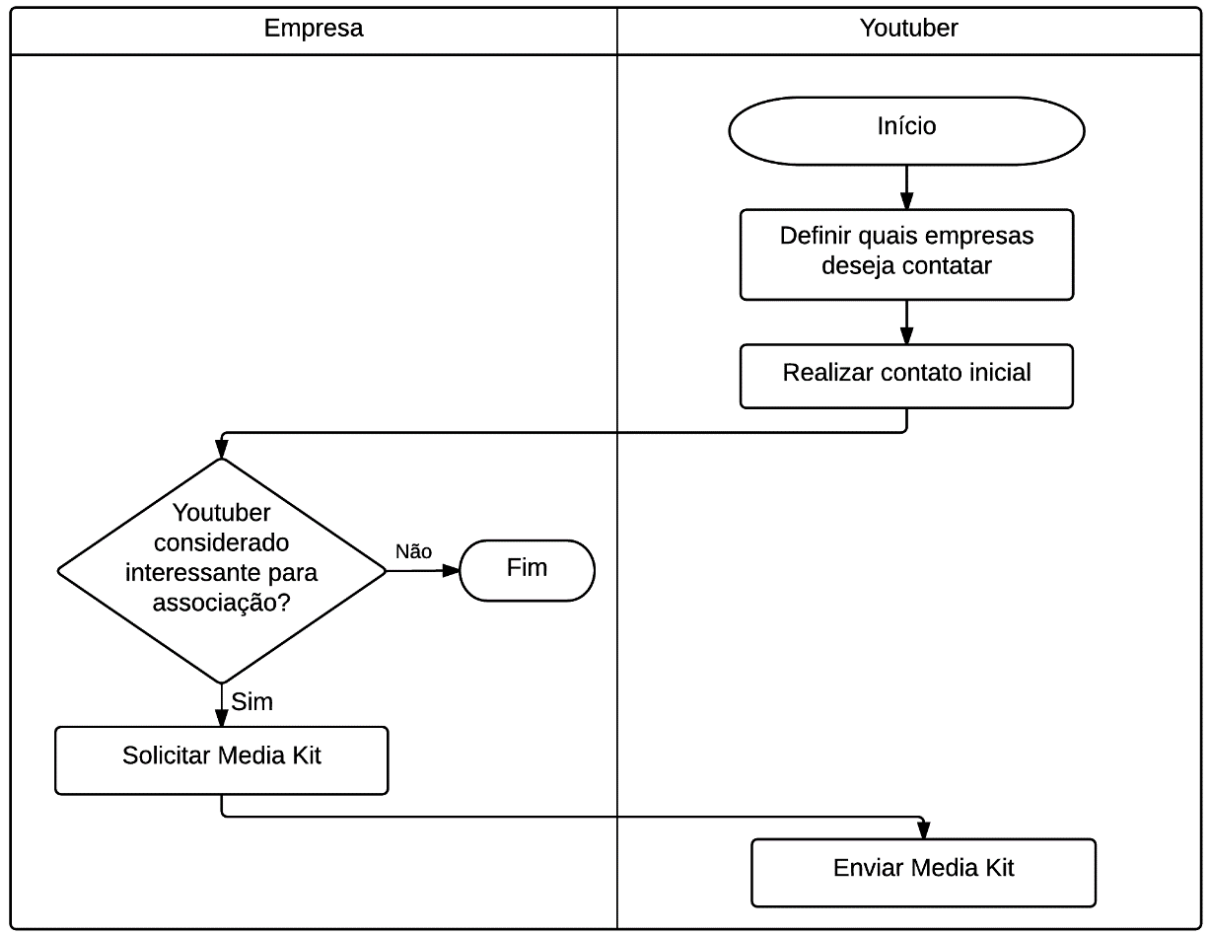

Fonte: Elaborado pelos autores (2015)

De acordo com a Youtuber 1, alguns geradores de conteúdo pecam ao realizar o contato inicial, ao pedirem brindes e produtos para a marca, enquanto deveriam se apresentar Revista de Gestão e Secretariado-GeSec, São Paulo, v. 8, n. 3, p 228-248, Mai./Ago. 2017. 
e convidá-la para conhecer seu trabalho. Neste momento, é importante que estes geradores não se precipitem, primeiramente gerando conteúdo de qualidade e consolidando seu público, para então buscarem marcas para se associar.

A Empresa D afirma que muitos geradores de conteúdo entram em contato, e a Empresa A declara que, mesmo nestes casos, costuma avaliar as informações deste gerador e o seu perfil de trabalho, para então decidir se deseja se associar. A Youtuber 2 acrescenta ao afirmar que há empresas que preferem trabalhar com geradores iniciantes, pois não cultivam certos vícios e podem possuir um público diferenciado. Por fim, a Youtuber 1 alega que não costuma realizar esse contato inicial porque não sabe como fazê-lo, apesar de acreditar que o ideal seria ter uma postura mais proativa e não ficar apenas esperando uma iniciativa das marcas.

\subsubsection{Negociação}

A segunda etapa começa com a avaliação tanto por parte da marca, como do gerador de conteúdo. As marcas avaliam as informações que constam no media kit enviado pelo youtuber e após essa avaliação decidem se desejam realizar a associação ou não. Os geradores de conteúdo, por sua vez, avaliam se a associação é interessante e se há compatibilidade entre a marca e seu público. As youtubers 1, 2 e 3 afirmam que os principais aspectos que avaliam são a qualidade do produto e a relevância para o conteúdo. Caso a associação seja considerada interessante, youtubers e marcas decidirão o formato da parceria, ou seja, quais serão as ações realizadas, caso contrário a empresa retorna ao monitoramento das mídias sociais (Figura 2A) a fim de encontrar o gerador de conteúdo ideal. Dos tipos de eventos possíveis, podem ser realizadas ações no ponto de venda. A curadoria e o licenciamento de produtos também são formatos que a associação pode assumir.

Com o formato de parceria decidido, definem-se as condições para que a parceria seja realizada, horário e informações que devem constar no conteúdo, entre outros detalhes. A Empresa B afirma que exige a revisão de publiposts antes que eles sejam divulgados. Por outro lado, as empresas A, C e D afirmam que não exigem revisão do conteúdo, pois entendem que a liberdade que os youtubers possuem ao gerar o conteúdo é muito importante nesse tipo de comunicação.

As condições também podem variar de acordo com o formato de parceria. No caso de tutoriais e resenhas, as Youtubers 1 e 3 afirmam que não submetem o conteúdo gerado para revisão da empresa, pois divulgam sua opinião real sobre o produto ou marca. Algumas marcas solicitam ao youtuber para que informe ao público que aquele conteúdo é patrocinado. As Youtubers 1 e 3 dizem que na maioria das vezes as marcas solicitam que o conteúdo seja identificado como publicidade, e que elas fazem essa identificação mesmo quando não é solicitado. A Empresa A afirma que, dependendo do tipo de ação, solicita que o conteúdo seja identificado como publicidade. Por outro lado, especialmente junto à Empresa D, a identificação da ação como publicidade é um aspecto essencial para a construção de um relacionamento de confiança com os consumidores, baseado na ética e transparência.

A elaboração e o fechamento do contrato encerram a etapa de negociação, representada na figura 3. Como há uma diversidade de possibilidades para a realização das ações, notou-se que nem todas são regidas por contrato. Geralmente em ações mais simples, informais e pontuais existem empresas e geradores de conteúdo que não veem a necessidade de contratos, e seguem diretamente para a realização da ação publicitária, representada na Figura 4. Para tais empresas e youtubers, contratos são exigidos apenas em casos de associações mais complexas e duradouras. Nesse sentido, a Youtuber 1 afirma que a

Revista de Gestão e Secretariado - GeSec, São Paulo, v. 8, n. 3, p 228-248, Mai./Ago. 2017. 
existência de um contrato beneficia a ambos, pois é um modo de garantir o que será contratado pela empresa, e o que será realizado pelo gerador. A Youtuber 2 afirma que trabalha com um contrato pré-estabelecido, e que altera as cláusulas de acordo com tipo serviço contratado.

Figura 3: Subprocesso Negociação

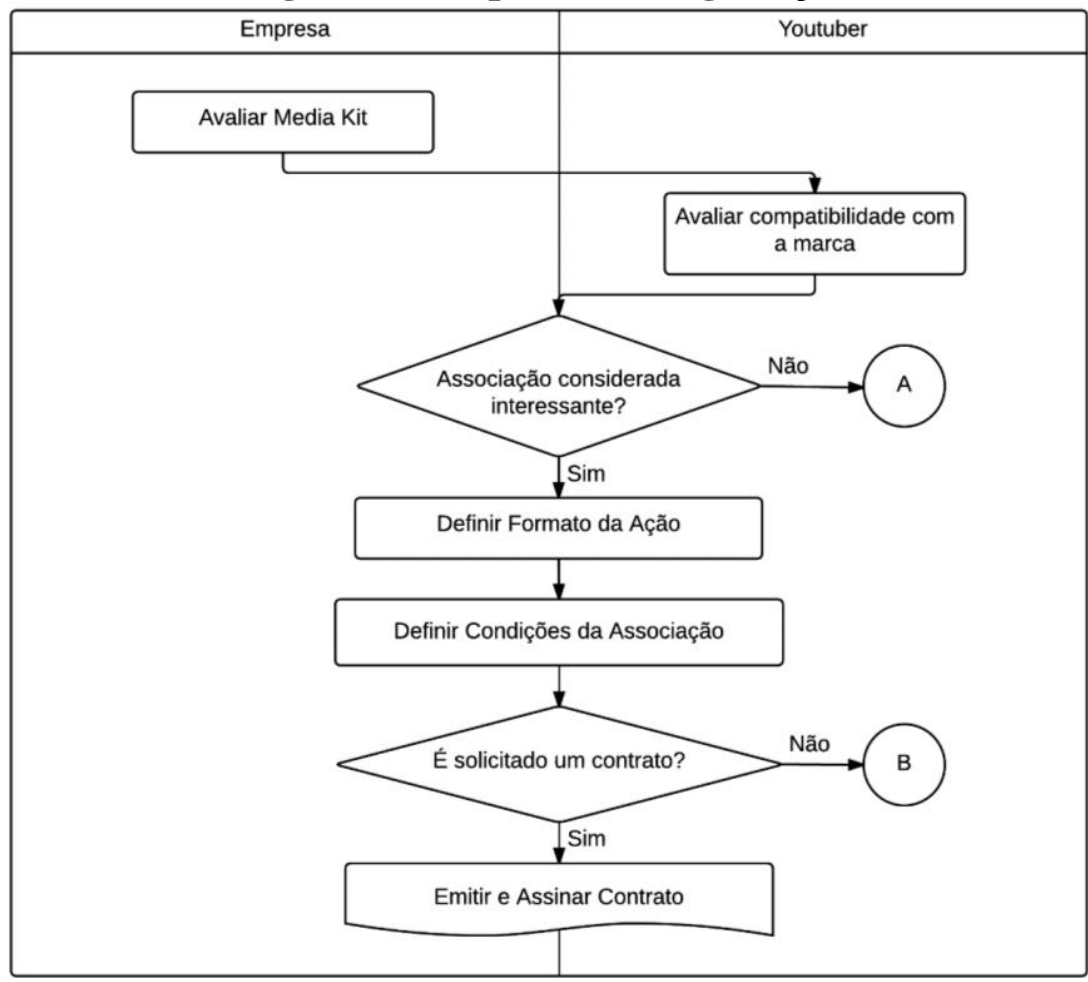

Fonte: Elaborado pelos autores (2015)

\subsubsection{Ação}

A terceira etapa, representada na figura 4, consiste na realização da ação definida entre youtuber e marca, de acordo com as condições mencionadas na etapa anterior. Além dos materiais mencionados por Didone (2014), constatou-se que pode ser enviado um briefing com o objetivo da ação, ou press release, a fim de dar todo o suporte necessário à realização da ação.

Figura 4: Subprocesso Ação

\begin{tabular}{|l|l|}
\hline Empresa & Youtuber \\
\hline $\begin{array}{c}\text { Enviar meios necessários } \\
\text { para realizar ação }\end{array}$ & \\
\hline
\end{tabular}

Fonte: Elaborado pelos autores (2015)

Entre os principais formatos de vídeos em que marcas estão inseridas ou são mencionadas, estão os seguintes: tutoriais, resenhas, recebidos, unboxing e publiposts. Enquanto nos vídeos de recebidos a marca é apenas mencionada, em vídeos de resenhas são apresentadas opiniões e recomendações do produto. Em tutoriais são apresentadas instruções

Revista de Gestão e Secretariado - GeSec, São Paulo, v. 8, n. 3, p 228-248, Mai./Ago. 2017. 
de uso e opiniões sobre produtos e marcas, e no caso de publieditoriais, o foco está na criação de conteúdo voltada para a promoção da marca.

Notou-se também que a associação entre marcas e youtubers não inclui apenas a inserção da marca no conteúdo em vídeo, mas também pode assumir outras formas, visto que geradores possuem notoriedade e popularidade entre o seu público. Deste modo, a associação sai do ambiente exclusivamente online e assume formatos como a criação de conteúdo para as mídias sociais da marca, a participação em campanhas publicitárias, a co-criação de produtos, e a participação em eventos, além de formatos não mencionados na literatura, como a curadoria de produtos da marca e o licenciamento de produtos.

$\mathrm{Na}$ criação de conteúdo para mídias sociais e na participação dos youtubers em campanhas publicitárias, as marcas buscam uma comunicação direta com seu público-alvo, para isto utilizando a popularidade dos youtubers. No caso da co-criação, os youtubers participam do desenvolvimento de uma linha especial de produtos, de determinada marca, que carregam o seu nome. Estes produtos podem ser roupas ou cosméticos, por exemplo, e por conterem características e estilo de determinado youtuber, podem ser comprados pelo público que se identifica com ele e o admira. Além da participação na criação dos produtos, os youtubers podem produzir vídeos sobre o lançamento dos produtos, mostrando detalhes, especificações, modo de funcionamento, dicas de utilização e benefícios dos produtos. Outra forma de ação é a presença dos youtubers em pontos de venda e eventos da marca, tais como encontros, feiras, workshops e palestras. Neste tipo de ação, o principal objetivo é divulgar a marca e engajar o público.

Constatou-se que marcas e youtubers também podem se associar por meio da curadoria e do licenciamento de produtos. No caso da curadoria, os produtos de determinada marca são selecionados pelos youtubers a fim de criar uma seleção de produtos aprovados e utilizados por ele. Para isto, as marcas apresentam produtos pré-selecionados, e a partir dessa pré-seleção são escolhidos os produtos preferidos para integrar uma coleção com o nome do youtuber. Quanto ao licenciamento de produtos, a marca utiliza produtos já existentes e cria linhas com o nome do youtuber, buscando agregar valor ao produto e torná-lo mais reconhecido.

\subsubsection{Remuneração}

A quarta etapa é a remuneração, que pode variar de acordo com o tipo de parceria estabelecida. O youtuber pode ser remunerado com produtos, monetariamente por uma determinada ação, ou pode receber royalties, no caso de ações de médio e longo prazo. A remuneração por meio de produtos acontece quando a empresa envia produtos ao youtuber como forma de pagamento pela ação que será realizada. Esse tipo de remuneração geralmente acontece com itens mais caros, como por exemplo produtos eletrônicos.

A Empresa A afirma que a remuneração varia de acordo com o formato de trabalho de cada youtuber, enquanto a Empresa D declara que realiza o processo de remuneração conforme normas fiscais inerentes a qualquer processo de prestação de serviços, com a emissão de notas fiscais de serviço e pagamentos por meio de boletos ou depósitos bancários.

A Empresa C, por trabalhar com a coautoria, remunera os youtubers por meio de royalties. Neste caso, promover os produtos é interessante tanto para Empresa como para o youtuber, pois quanto maior for o volume de vendas da linha de produtos assinado por ele, maior será o valor recebido. Entretanto, a Youtuber 1 acredita que esta forma de remuneração não possui um bom custo-benefício para o youtuber pois, apesar de não precisar realizar 
investimentos e o retorno ser de curto prazo, o youtuber recebe um percentual baixo se comparado com o lucro obtido pelas empresas.

\subsubsection{Avaliação e manutenção do relacionamento}

A quinta etapa consiste na avaliação e manutenção do relacionamento. A partir destas avaliações, as marcas podem conhecer o desempenho, identificar conteúdos em que a marca é citada, e entender o sentimento do consumidor em relação ao produto.

A Empresa D afirma que mensalmente avalia as ações realizadas, e que a partir destas avaliações consegue entender o comportamento do consumidor no ambiente online, e saber qual tipo de ação está surtindo mais efeito com os consumidores, além de identificar pontos de melhoria e até mesmo obter ideias para novos produtos. A Empresa A afirma que ferramentas como Google Analytics, Google Adwords e ferramentas existentes dentro das redes sociais são os principais métodos utilizados, e que além deles também utiliza tags para o monitoramento do número de cliques. A Empresa B declara que adota como métricas para avaliação o número de vendas resultantes de cada ação, o número de visitas ao site, o número de pedidos e a audiência das ações.

Quanto aos youtubers, o principal método utilizado para avaliar a associação a uma marca é a resposta dos consumidores. A Youtuber B afirma que o mais importante é a opinião do público, enquanto a Youtuber $\mathrm{C}$ afirma que realiza essa avaliação por meio do número de visualizações dos vídeos, do número de "gostei”, e do engajamento do público.

Conforme apresentado na figura 5, após a avaliação das ações realizadas, as marcas podem saber quais ações obtiveram um resultado positivo e foram rentáveis. Nestes casos, as marcas procuram estabelecer um relacionamento com os geradores de conteúdo para a formação de parcerias futuras. Do mesmo modo, os youtubers também avaliam as ações realizadas e decidem se irão estabelecer um relacionamento com as empresas ou não.

\section{Figura 5: Subprocesso Avaliação e Manutenção de Relacionamento}

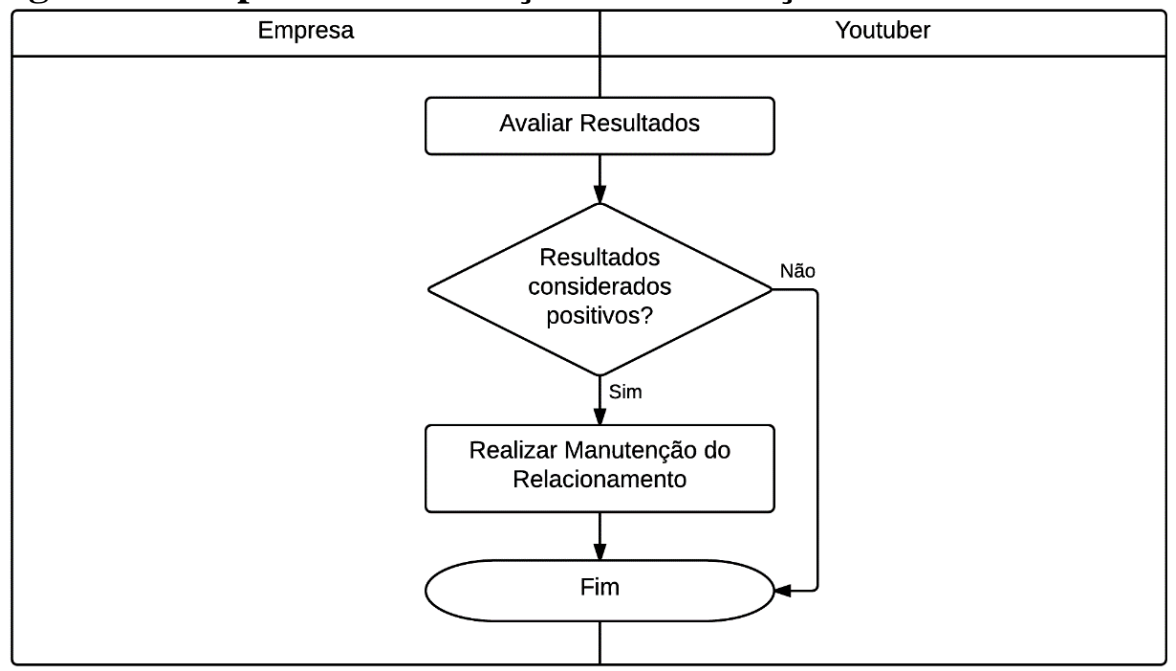

Fonte: Elaborado pelos autores (2015)

\section{CONSIDERAÇÕES FINAIS}

O objetivo do presente artigo é compreender e descrever o processo de associação entre marcas e geradores de conteúdo no YouTube. Para o alcance deste objetivo, foi 
realizada uma pesquisa qualitativa, de caráter descritivo, e que utiliza a estratégia de casos múltiplos. Os dados secundários foram coletados por meio da observação sistemática dos principais canais ligados ao segmento de moda e beleza, enquanto que os dados primários foram obtidos por meio de entrevistas semiestruturadas com youtubers e empresas com as quais estes se relacionam.

Do ponto de vista da caracterização do processo de associação entre marcas e geradores de conteúdo no YouTube, observou-se a existência de 5 etapas principais: Contato, Negociação, Ação, Remuneração, e Avaliação e Manutenção do Relacionamento. Neste sentido, observou-se a importância do gerador de conteúdo como parte realizadora ipso facto das atividades de comunicação de marketing, por meio da criação de vídeos para seus próprios canais. Porém, ficou evidenciado que as organizações ainda possuem maior controle do processo como um todo, já que, na maioria dos casos, são elas que definem a existência ou não da associação, bem como os métodos de associação possíveis, inclusive no que diz respeito às formas de recompensa a serem fornecidas aos youtubers.

Em relação aos youtubers, constatou-se que os entrevistados vêm obtendo sua renda a partir da atuação no YouTube, e das oportunidades que o canal proporciona. No entanto, o cenário online e de mídias sociais é dinâmico, e está em constante evolução, e desta maneira, é preciso acompanhar as mudanças e se reinventar. Neste sentido, percebeu-se que há diversas oportunidades para que youtubers desenvolvam seu lado empreendedor. Como exemplo, é possível mencionar casos de youtubers que estão lançando livros, marcas ou negócios próprios, aspectos que acabam influenciando no equilíbrio de forças, durante o processo de associação com marcas, a favor de youtubers que tenham consolidado como marcas fortes no ambiente virtual.

Do ponto de vista das organizações, percebeu-se que a associação com youtubers possui diversas possibilidades a serem exploradas, pois além de ser uma ação que possui um custo baixo se comparado a outras mídias, permite que se alcance diretamente o seu públicoalvo por meio de um influenciador. Também observou-se que diversas empresas do segmento de moda e beleza estão adotando a associação com geradores como parte de sua estratégia de marketing, pois além de obterem um aumento no volume de vendas, tal estratégia influencia a imagem que o público tem da marca, e permite que a marca se posicione diante do mercado, além de ser reconhecida e lembrada.

Desta forma, entre as principais contribuições deste artigo, está a possibilidade de conhecer melhor como acontecem as associações entre marcas e geradores de conteúdo. $\mathrm{Ou}$ seja, as empresas e geradores que não realizam esta atividade podem aprender a fazê-lo, e aqueles que realizam podem aperfeiçoar suas práticas, a fim de potencializar seus resultados, e melhorar o modo com a associação acontece.

Visto que o processo de associação é recente, cabe tanto às empresas quanto aos geradores de conteúdo consolidar esta relação a cada dia, de modo que ela renda resultados cada vez melhores para ambas as partes. Tal relação que hoje é conhecida como parceria, deve passar a ser compreendida como uma relação comercial, onde há direitos e deveres, bem como interesses envolvidos. Deste modo, a associação deve se tornar cada vez mais profissional, deixando de ser algo oculto, e que não é comentado, sempre mantendo a transparência e o bom relacionamento com o público.

Entre as limitações encontradas durante a realização do trabalho estão a pouca literatura existente sobre geração de conteúdo no YouTube; a falta de dados consolidados que subsidiem eventuais análises; a dificuldade em obter informações de organizações, pois este é um tema estratégico para elas; a dificuldade em entrar em contato com youtubers, e o receio que estes geradores possuem em falar sobre este assunto. É relevante mencionar que a grande dificuldade em abordar este assunto acontece porque geradores de conteúdo são criticados por

Revista de Gestão e Secretariado - GeSec, São Paulo, v. 8, n. 3, p 228-248, Mai./Ago. 2017. 
se associarem com marcas e, principalmente, por serem remunerados, pois há consumidores que desconfiam da credibilidade do conteúdo quando há publicidade.

Para pesquisas futuras, são sugeridas a realização de estudos quantitativos a fim de mensurar o retorno alcançado por empresas que realizam a associação com youtubers; a aplicação e adaptação do modelo sugerido a outros segmentos, como o de games, culinária e humor; além do desenvolvimento de modelos que auxiliem empresas no momento de escolher o gerador de conteúdo mais adequado para se associar.

\section{REFERÊNCIAS}

Belch, G. E. and Belch, M. A. (2008). Advertising and Promotion: An Integrated Marketing Communications Perspective (8a ed.). New York: McGraw-Hill.

Berthon, P. R., Pitt, L. F., Plangger, K. and Shapiro, D. (2011). Marketing meets Web 2.0, social media, and creative consumers: Implications for international marketing strategy. Business Horizons, 55, 261-271. 09

Bolotaeva, V. and Cata, T. (2011). Marketing Opportunities with Social Networks. Journal of Internet Social Networking and Virtual Communities. 2011, 1-7. DOI: $10.5171 / 2011.409860$

Boni, V. and Quaresma, S. J. (2005). Aprendendo a entrevistar: como fazer entrevistas em Ciências Sociais. Revista Eletrônica dos Pós-Graduandos em Sociologia Política da UFSC, 2 (1), 68-80. Recuperado em 18 setembro, 2015 de http://www.emtese.ufsc.br/

Bruhn, M., Schoenmueller, V. and Schafer, D. B. (2012). Are social media replacing traditional media in terms of brand equity creation? Management Research Review, 35 (9), 770 - 790. DOI: 10.1108/01409171211255948

Bughin, J., Doogan, J. and Vetvik, O. J. (2010). A new way to measure word-of-mouth marketing. Marketing and Sales Practice. McKinsey Quartely.

Burgess, J., and Green J. (2009). The entrepreneurial vlogger: Participatory culture beyond the professional amateur divide. In: Snickars, P.; Vonderau, P. The YouTube Reader, 88-107. Stockholm: National Library of Sweden.

Carreira, L. M. C. (2014). A publicidade na relação entre leitor e blogueiro: um estudo sobre os blogs de moda da plataforma $F^{*}$ Hits. Brasília: Universidade de Brasília.

Casaló, L., Flavián, C. and Guinaliú, M. (2011). Understanding the intention to follow the advice obtained in an online travel community. Computers in Human Behavior, 27, 622-633. DOI: 10.1016/j.chb.2010.04.013

Castro, I. T. V. M. N. (2013). O comportamento gerencial do blogueiro sob a perspectiva da teoria de redes sem escalas. Brasília: Universidade de Brasília.

Chu, S. and Kim, Y. (2011). Determinants of consumer engagement in electronic wordof-mouth (eWOM) in social networking sites. International Journal of Advertising, 30, 47-75. DOI: $10.2501 / \mathrm{IJA}-30-1-047-075$

Revista de Gestão e Secretariado - GeSec, São Paulo, v. 8, n. 3, p 228-248, Mai./Ago. 2017. 
Constantinides, E. and Fountain, S. J. (2008). Web 2.0: Conceptual foundations and marketing issues. Journal of Direct, Data and Digital Marketing Practice, 9 (3), 231-244. DOI: $10.1057 /$ palgrave.dddmp.4350098.

Dhar, V. and Chang, E. (2009). Does Chatter Matter? The Impact of User-Generated Content on Music Sales. Journal of Interactive Marketing, 23, 300-307. DOI: 10.1016/j.intmar.2009.07.004

Didone, S. C. (2014). A influência dos blogs de moda no comportamento do consumidor. Porto Alegre: Universidade Federal do Rio Grande do Sul.

Drury, G. (2008). Opinion piece: Social media: Should marketers engage and how can it be done effectively? Journal of Direct, Data and Digital Marketing Practice, 9 (3), 274-277. DOI: $10.1057 /$ palgrave.dddmp.4350096.

Fernandes, B. G. and Rosa, C. O. (2013). As métricas do marketing no século XXI. Revista Panorama 3 (1), 180-190. Recuperado em 05 outubro, 2015 de http://revistas.ucg.br/index.php/panorama/article/view/3435.

Fournier, S. and Avery, J. (2011). The uninvited brand. Business Horizons, 54, 193-207. DOI: $10.2139 / \mathrm{ssrn} .1963056$

Gil, A. C. (2008) Métodos e Técnicas de Pesquisa Social (6ª edição). São Paulo: Atlas.

Gurau, C. (2008). Integrated online marketing communication: implementation and management. Journal of Communication Management, 12 (2), 168-184. DOI: $10.1108 / 13632540810881974$.

Hinerasky, A. D. (2014, outubro). O Instagram Como Plataforma De Negócio de Moda: dos "itbloggers" às "it-marcas". Anais do Congresso Internacional Comunicação $e$ Consumos, São Paulo, 4.

Kotler, P. and Keller, K. L. (2011). Administração de Marketing: A Bíblia do Marketing. (12a ed.). São Paulo: Pearson Prentice Hall.

Minayo, M. C. S., Assis, S. G. and Souza, E. R. (2010). Avaliação por triangulação de métodos: Abordagem de Programas Sociais. Rio de Janeiro: Fiocruz.

Monçale, A. M., Gomes, W. and Arruda Neto, E. (2015, junho). Blogueiro como Ferramenta de Marketing. Anais do Congresso de Ciências da Comunicação na Região Centro-Oeste, Campo Grande, 17.

Neisser, D. (2004). Guerrilla marketing can build brand relationship (Vol. 89, pp. 4).

Oh, J., Susarla, A. and Tan, Y. (2008). Examining the diffusion of user-generated content in online social networks. Seattle.

Parise, S. and Guinan, P. (2008, January). Marketing using Web 2.0. Proceedings of the $41^{\text {st }}$ Hawaii International Conference on System Sciences. Waikoloa, HI, USA.

Revista de Gestão e Secretariado - GeSec, São Paulo, v. 8, n. 3, p 228-248, Mai./Ago. 2017. 
Pinho, A. and Ferreira, J. C. (2014). Avaliação do perfil do consumidor que escolhe produtos de beleza por meio das redes sociais sob a ótica da etnografia digital. Anais do Congresso Internacional Interdisciplinar em Sociais e Humanidades, Salvador, 3.

Pookulangara, S. and Koesler, K. (2011) Cultural influence on consumers' usage of social networks and its' impact on online purchase intentions. Journal of Retailing and Consumer Services, 18, 348-354. DOI: 10.1016/j.jretconser.2011.03.003

Potluri, R. M. (2008) Assessment of effectiveness of marketing communication mix elements in Ethiopian service sector, African Journal of Business Management, 2 (3), 59-64.

Prodanov, C. C. and Freitas, E. C. (2013). Metodologia do trabalho científico: métodos e técnicas da pesquisa do trabalho acadêmico. (2a edição). Novo Hamburgo: Editora Feevale.

Rowley, J. (2004). Just another channel? Marketing communications in e-business. Marketing Intelligence \& Planning, 22 (1), 24 - 41. DOI: 10.1108/02634500410516896

Sebastião, S. (2011). Formatos da publicidade digital: sistematização e desambiguação. Comunicação e Sociedade, 19, 13-24. DOI: 10.17231/comsoc.19(2011).894

Singh, T., Veron-Jackson, L. and Cullinane, J. (2008). Blogging: A new play in your marketing game plan. Business Horizons, 51, 281-292. DOI: 10.1016/j.bushor.2008.02.002

Shao, G. (2009). Understanding the appeal of user-generated media: a uses and gratification perspective. Internet Research, 19, 7-25. DOI: 10.1108/10662240910927795

Schmallegger, D. and Carson, D. (2007). Blogs in tourism: Changing approaches to information exchange. Journal of Vacation Marketing, 14 (2), 99-110. DOI: $10.1177 / 1356766707087519$

Smith, A. N., Fischer, E. and Yongjian, C. (2012). How does brand-related usergenerated content differ across YouTube, Facebook, and Twitter? Journal of Interactive Marketing, 26, 102-113. DOI: 10.1016/j.intmar.2012.01.002

Winer, R. S. (2009). New Communications Approaches in Marketing: Issues and Research Directions. Journal of Interactive Marketing, 23, 108-117. 0

Yin, R. K. (2001). Estudo de Caso: Planejamento e Métodos. (2 ${ }^{\mathrm{a}}$ ed.). Porto Alegre: Bookman, 


\section{APÊNDICE 1 - ROTEIROS DE ENTREVISTAS}

\subsection{YOUTUBERS}

1. Além do YouTube, em quais mídias sociais você está presente? (Ex.: Twitter, Facebook, Snapchat, Instagram, Periscope, Pinterest, YouTube, Blog)

2. O seu canal no YouTube e seus vídeos se encaixam em qual segmento? (Ex.: Moda, Beleza, Tecnologia, Estilo de Vida, Música, Comportamento)

3. Quais formatos de vídeos você mais produz? (Ex.: Vlogs, Bate-papo, Tutoriais, Tag)

4. Como você caracteriza o seu público? (Ex.: idade, sexo, características comportamentais)

5. Como usuária do YouTube, você costuma assistir, avaliar e comentar vídeos? Se sim, poderia citar alguns de seus canais preferidos?

6. Atualmente, ser youtuber/gerador de conteúdo é a sua profissão? Ou você concilia a sua profissão convencional com o canal?

7. Já realizou parcerias com marcas para criação de conteúdo em vídeo?

8. Atualmente, você possui marcas associadas ao seu canal? Se sim, poderia citar algumas?

9. Como essa parceria pode ser vista nos seus vídeos? (Ex.: Apresentação do produto, dicas de como usar, criação de conteúdo em parceria, tutorial, apresentação dos lançamentos da marca.)

10. Quais segmentos de empresa mais entram em contato para realização de parceria? (Ex.: Moda, Beleza, Decoração, Tecnologia, etc.)

11. Como você costuma realizar relações comerciais com empresas e marcas?

a. A empresa ou o você costuma entrar em contato para fazer uma proposta?

b. Como é decidido o modo como a marca será mencionada? A empresa sugere ou você escolhe o formato que considera mais adequado? (Ex.: se será um tutorial, um vídeo explicativo, um post, um evento, a criação de um produto assinado por você)

c. Você realiza algum tipo de contrato formal? A associação possui um período delimitado de duração?

12. Que critérios você considera para se associar ou não à uma marca? (Ex.: segmento empresa, popularidade, identificação com público, etc.)

13. Muitos blogueiros possuem um media kit com informações sobre o seu público, número de assinantes e outras informações que podem ser encaminhadas para possíveis parceiros. Você possui um media kit com informações do seu canal?

Revista de Gestão e Secretariado - GeSec, São Paulo, v. 8, n. 3, p 228-248, Mai./Ago. 2017. 
14. Que tipo de resultados e benefícios uma marca pode obter ao anunciar em um canal no YouTube?

15. Para você, como youtuber, quais os benefícios de possuir marcas que são associadas ao seu canal?

16. O que você acredita que atrai uma marca que deseja se associar à você? (Ex.: tipo público, número visualizações, engajamento)

17. Geralmente, as marcas solicitam que o conteúdo seja sinalizado como publicidade?

\subsection{EMPRESAS}

1. Qual é o nome da empresa?

2. Em qual segmento de mercado atua?

3. Está presente nas redes sociais? Se sim, em quais?

4. Como é selecionado o gerador de conteúdo para associação? Quais são os principais fatores que são considerados nessa escolha?

5. Qual é o tipo de associação que a empresa realiza com os geradores de conteúdo?

6. Existe algum controle por parte da empresa sobre o que é publicado pelos geradores de conteúdo? A empresa fornece produtos e informações que devem ser mencionadas ou exibidas no conteúdo publicitário?

7. Como é feita a remuneração para que os geradores de conteúdo produzam posts e vídeos com conteúdo publicitário?

8. A empresa exige que os vídeos patrocinados sejam identificados como conteúdo publicitário?

9. Em relação aos vídeos patrocinados, porque não existem links de redirecionamento para o canal da empresa no YouTube?

10. Em relação a estratégia de comunicação de marketing da empresa, qual a importância da presença no YouTube e da associação com geradores de conteúdo?

11. Como o YouTube se destaca das demais mídias sociais? Quais as vantagens de expor a sua marca nesta plataforma em relação à outras mídias como o Facebook e o Instagram?

12. Existe alguma métrica que mede o desempenho e o retorno destas ações para a empresa?

13. Quanto a parceria com youtubers representa em ganho para a marca? 